\author{
GILBERT HARDY
}

\title{
La espiritualidad en Oriente y Occidente*
}

\begin{abstract}
Diálogo continuo e intensificado, apertura del Espíritu y obediencia con fe se necesitan para que el diálogo religioso OrienteOccidente eventualmente favorezca tanto a Oriente como a Occidente.
\end{abstract}

I EJANOS están los tiempos cuando los cristianos podían 1 vivir su fe completamente aislados de la molesta presencia de "otras religiones". En aquella remota era de espiritualidad interna la cuestión del encuentro con religiones no-cristianas se consideraba dominio exclusivo de los historiadores de religiones, o si no, se le aparecía al cristiano educado con las biografías de santos y mártires de la fe. Además, en el pasado los encuentros religiosos estaban generalmente cargados de implicaciones políticas. Representaban, especialmente en el caso del islam, una amenaza política a la cristiandad. No es de extrañarse que el único diálogo al que dieron paso estos encuentros fuera el de la espada y que su arena fuera el campo de batalla militar.

Hoy el reto es más profundo y las formas de encuentro entre religiones, más sutiles. En nuestra era de comunicación instantánea no hay barreras para evitar que las ideas crucen el planeta y una conciencia más profunda de nuestra pertenencia a la misma familia humana hace no sólo más fácil, sino también más deseable una cierta interfertilización de peculiaridades culturales entre las naciones. La religión no puede considerarse exenta de esta corriente. El hecho es, nos guste o no, que las religiones orientales ya han afectado hondamente nuestro patrimonio espiritual de Occidente ${ }^{1}$ y que, al mismo tiempo, Oriente, también, posiblemente por primera vez en la historia,

* Traducción de Jorge Hernández.

1 Desde luego esto debe ser entendido dentro del contexto del diálogo EsteOeste. El cristianismo no es, ni ha sido, exclusivamente de Occidente. 
está acercándose cada vez más a Occidente con el fin de ser instruido por la herencia espiritual cristiana. ${ }^{2}$

Es fácil ver por qué este nuevo estado del asunto tiene una naturaleza ambivalente. Puede presagiar una indiferencia religiosa, pero también puede indicar un pacto de paz y una nueva era de lúcido entendimiento entre las religiones del mundo. Pero entonces ¿qué postura debemos tomar nosotros, como cristianos, a este respecto?

Sin embargo, antes de discutir esto, y para efectos de mi argumento definiré la religión como el intento permanente del hombre (esto es, de la humanidad) de alcanzar la perfección más elevada. ${ }^{3}$ Generalmente, aunque no universalmente, la idea de perfección más elevada está fusionada con la idea de algún tipo de unión con aquello que es lo más perfecto o con el Uno más perfecto. Por espiritualidad, por otro lado, entenderé la suma total de las creencias y actitudes que entran en la realización de la búsqueda religiosa. Obviamente que cualquier espiritualidad dada también engloba todas las presuposiciones teóricas (la ideología) de la religión particular que representa: ${ }^{4}$ Esto me dará más libertad para hablar en lo sucesivo alternativamente de religiones no-cristianas o de espiritualidades no-cristianas, dependiendo del énfasis que desee darle a los aspectos más teóricos o más prácticos de la búsqueda religiosa.

El problema teórico que respalda ahora la facilidad o la dificultad del cristiano que observa el presente surgimiento de diálogos interreligiosos es éste: ¿ son contradictorias, contrarias o complementarias las diferentes religiones?

Y de nuevo, tomadas todas juntas, ¿ cómo se relacionan con el cuerpo de creencias y prácticas cristianas? ¿ Puede haber, por ejemplo, algún tipo de diálogo entre el Occidente

${ }^{2}$ El creciente número de encuentros, simposios y servicios de meditación es verdaderamente asombroso. Los boletines del Consejo Norteamericano del diálogo Este-Oeste (Sand Springs, Okla.) reportan, con frecuencia, los hechos más recientes en los Estados Unidos.

${ }^{3}$ Esta definición no menciona el nombre de Dios intencionadamente ya que esto excluiría cualquier diálogo con el budismo. Pero es por lo menos discutible que la "búsqueda de" la mayor perfección implica siempre la búsqueda de Dios.

- Por lo tanto, la espiritualidad como tal engloba las caracteristicas de religión tanto en un sentido objetivo como subjetivo. Es la experiencia vivida y concreta de ser religioso. 
cristiano y el Oriente hindú o budista? La pregunta es de gran importancia, pues cualquier diálogo que no es acompañado por lo menos con alguna esperanza de entendimiento y que no es respaldado por un sentido de legitimidad sólo se está dirigiendo hacia una catástrofe.

Puede ser útil en este punto recordar algunas reglas elementales de lógica. Las proposiciones contradictorias no pueden ser válidas juntas, así como nada puede ser y no ser al mismo tiempo cuando se le juzga desde la misma perspectiva. Sin embargo, las proposiciones contrarias dejan lugar para algún tertium quid, una síntesis mayor, normalmente realizada en alguna forma del ser más rica y sofisticada. Estas indican, al igual que todas las proposiciones complementarias, la imperfección del planteamiento o la riqueza inherente a la cosa en cuestión, riqueza que no puede ser captada en una idea o no puede ser realizada en un planteamiento.

Lo que se aplica al orden cognoscitivo también se aplica al orden de acción y a las manifestaciones externas. Las posiciones y las actitudes pueden también ubicarse en cualquiera de las tres interrelaciones antes mencionadas. Nuestra pregunta es, entonces, si una espiritualidad no-cristiana es, por definición, opuesta a la espiritualidad cristiana, o si puede serle complementaria. Deseo formular específicamente esta pregunta con respecto a la posible relación entre las espiritualidades del budismo zen y el cristianismo. Más adelante tocaré este punto.

Antes de proseguir es necesaria una distinción adicional: cualquier religión puede apreciarse en dos niveles, de acuerdo a la luz que la ilumina. Iluminadas como estaban con una luz tenue, las religiones sólo aparecen como formas o variaciones de la búsqueda humana de la perfección, como manifestaciones del permanente anhelo del alma de alcanzar un mejor estado. ${ }^{5}$ Pero cuando son iluminadas por una luz mayor, se manifiestan, en sus particularidades, como religiones de un credo particular y de un código definido de comportamiento.

Equipados con estas herramientas conceptuales, asumamos dos declaraciones que propongan la postura cristiana respecto de otras religiones: todas las religiones son testigo, aunque en diferentes grados, del viaje de la humanidad hacia Dios. 
A través de sus espiritualidades particulares, incluso las religiones no-cristianas pueden ayudarnos a una mejor comprensión de la verdad de la revelación. La limitación de este ensayo sólo me permite hacer unas pocas sugerencias tomadas de la reciente enseñanza de la Iglesia y del vasto material de religión comparada.

\section{Todas las religiones son testigos vivientes del camino de la humanidad hacia Dios}

Para fortuna del cristiano contemporáneo, la Iglesia ha delimitado claramente su posición en Nostra aetate, Declaración de las relaciones de la Iglesia con religiones no-cristianas, del Concilio Vaticano II, y en una lista continuamente creciente de pronunciamientos papales y otras declaraciones eclesiásticas de elevado nivel. El Concilio dice lo siguiente: ${ }^{5}$

Desde la Antigüedad hasta el presente, ha existido entre diversos pueblos una cierta percepción del poder oculto que revolotea sobre el curso de las cosas y sobre los eventos de la vida humana... Así, en el hinduismo los hombres contemplan el misterio divino y lo expresan con un inagotable florecimiento de mitos y a través de la búsqueda de una pesquisa filosófica. Buscan liberarse de la angustia de nuestra condición a través de prácticas ascéticas o profunda meditación o un vuclo amoroso y confiado hacia Dios. El budismo, en sus múltiples formas, reconoce la insuficiencia radical de este mundo cambiante. Enscña un camino por el cual los hombres, con un espiritu devoto y confiado, pueden u obtener un estado de libertad absoluta $u$ obtener un alumbramiento supremo por sus propios esfuerzos, o por ayuda más elevada. De igual manera, otras religiones para ser encontradas por todas partes intentan de distintas maneras responder a las incansables búsquedas del corazón humano proponiendo "formas", que consisten en enseñanzas, reglas de la vida y ceremonias sagradas. La Iglesia católica no rechaza nada que sea verdadero y sagrado en estas religiones. ${ }^{6}$

${ }^{5}$ A este respecto la religión manifiesta una caracteristica de la naturaleza humana y es estudiada desde la visión de la filosofia del hombre. Scheller lo llamó "el terno en el hombre".

6 Nostra Aetale. cap. 2. 
Se nota que el Concilio puso énfasis en el empuje religioso básico de cada religión -empuje que surge de "las incansables búsquedas del corazón humano", siguiendo la profunda introspección de San Agustín. El elemento común del corazón incansable, considerado como experiencia fundamental de la humanidad, es como un puente dorado que toca las costas de incluso religiones tan diferentes como el budismo y el cristianismo e hinduismo e islam. Así, la experiencia religiosa es, desde este punto de vista, una experiencia de búsqueda, de peregrinaje, en donde todos participan, marchando hacia la gloriosa Jerusalén. Esta ciudad puede ser llamada Grail, Nirvana o el Paraíso occidental -siempre es la consumación de paz, amor y unión. No es de extrañarse que los monasterios benedictinos a menudo muestren la inscripción. Pàx, Paz, sobre el portal. Jerusalén es una ciudad de paz. Y el gran Dogen Zenji dio a su monasterio budista el nombre de Eiheiji, que significa "el templo de eterna paz".?

La raíz más profunda de este anhelo de todas las religiones ha de ser encontrada en la naturaleza del espíritu o, más precisamente, en las ocultas energías de nuestra propia alma espiritual. Es propio del espíritu romper las limitaciones de la materia y buscar la autorréalización en un reino que comúnmente llamamos el reino de los valores. El movimiento del espíritu es hacia el infinito; su criterio es el de la perfección absoluta. La belleza estética es ya la huella del espíritu en cuestión; la fuente de las aspiraciones éticas está en los manantiales profundos del espíritu del hombre. Belleza estética, aspiraciones éticas y nuestra incansable búsqueda de la verdad y el entendimiento, como Platón y Aristóteles nos lo recuerdan, son todas, manifestaciones de la naturaleza espiritual del hombre. Pero sobre todo - punto que ha sostenido con fuerza Kierkegaardla búsqueda religiosa es lo que mejor indica la naturaleza espiritual del hombre o, a la inversa, dado que el alma humana es un alma espiritual, estamos, por nuestra propia naturaleza, comprometidos con la búsqueda religiosa. Esta es, finalmente, el significado del famoso dictado de Tertuliano, anima naturali-

T Este es.el templo de la provincia de Echizen y es aún el centro espiritual de la secta soto zen. 
ter Christiana, o del recordatorio inmortal de Agustín, "Nos has creado, Señor, para ti mismo". 8

De esta manera, entonces, la religión es el sedimento que deja la actividad del espíritu en el alma. De la misma manera que no hay un ser humano sin un alma espiritual, así tampoco hay un alma espiritual sin la potencialidad innata -la dynamis de Aristóteles- para la búsqueda religiosa. Así es como entiendo a Pablo cuando habla de la creación "quejándose en un gran acto de alumbramiento" con la esperanza de liberarse de su condición presente (Rom.8:22-23). Todas las religiones participan de este acto de "quejarse" y en eso todas son, de hecho, testigos vivientes del encaminamiento eterno de la humanidad hacia la gloriosa Jerusalén.

\section{Las religiones no-cristianas pueden (o no) ayudarnos a comprender mejor, y vivir más auténticamente, la verdad de la revelación}

La búsqueda religiosa del alma humana es una búsqueda concreta, articulada dentro de las diferentes religiones del mundo. Podemos lamentar el hecho de que hay tantas religiones en el planeta y podemos sentir culpa por la idea de que se han cometido tantas hostilidades a través de la historia de la humanidad en nombre de la religión. Pero demorarse en estos hechos sería un terrible error: de hecho, sería el desdén de una gracia que es únicamente nuestra, a saber, la gracia de la reconciliación y el entendimiento entre las religiones, la gracia de aprendizaje y disculpa mutuos. Pero debemos admitir que este momento de gracia está cargado de peligros dado que ahora podemos estar tentados a movernos de una actitud previa de rechazo total a una actitud de aceptación acrítica - postura que podría poner en peligro, o incluso traicionar, los tesoros de la palabra de Dios ocultos en los evangelios. El diálogo sólo puede ser fructífero si es sincero e intensamente indagatorio. Tal aventura intelectual-espiritual requiere de fidelidad a la tradición personal junto con la humildad de la apertura hacia otras convicciones. Un ejemplo de tal actitud ha sido dado reciente-

8 En este siglo filósofos como Bergson, Blondel, Jaspers y Marcel han dado testimonios similares. De Lubac, Rahner, Lonergan y otros le han dado una expresión teológica. 
mente por el arzobispo Jadot, presidente de la Secretaría de no-cristianos, cuando declaró: "Estoy consciente de la unicidad de la revelación de Cristo Jesús. No nos ha sido dado otro nombre para la salvación. Sin embargo, otras tradiciones religiosas pueden ayudarnos a una comprensión más profunda de todo lo que Jesús nos ha enseñado en la Iglesia por casi 2000 años." 9

¡Qué lejos está esta posición de la generalmente autocomplaciente actitud de la teología católica preconciliar! Hoy vemos cumplida la visión del Papa Juan XXIII : aire puro ha entrado en las antiguas bóvedas de la catedral. Lo que ha sido refrescado y rejuvenecido es una forma de pensar y un arte de amar dentro de la Iglesia: nos hemos movido de la quietud del rechazo al diálogo de los encuentros.

El diálogo religioso debe seguir ciertas reglas para ser fructífero. Estas expresan verbalmente esas predisposiciones en cl alma y esas actitudes mentales que son necesarias para estar adecuadamente "sintonizados" con la longitud de onda del compañero dialogante. Mencionaré aquí sólo cuatro reglas.

La primera regla es la empatía. Esta es la capacidad mental de entender una posición u observar una práctica desde dentro de la religión en cuestión. Para acercarse a una religión de esta manera se requiere de un aislamiento, de alejamiento, como si se tratara de nuestras propias convicciones religiosas. ${ }^{10}$ Este "alejamiento" sin embargo, no es retraimiento: la empatía no es la aceptación de la posición de los demás, sino una disposición y deseo de escucharla y apreciarla desde la postura de sus partidarios.

La segunda regla es la simpatía. Así como la empatía, la simpatía está, sin embargo, más en la voluntad que en el intelecto. Un interrogador simpático es un interrogador interesado, alguien cuyo verdadero interés es apropiarse la riqueza de la espiritualidad a la cual se le ha dado acceso. Además, la sim-

* Conscjo Norteamericano del diálogo Este-Oeste 17 (mayo 1983): 3. La atirmacion fuc hecha durante un seminario interreligioso llevado a cabo en marzo, en el seminario de la Inmaculada Concepción, en Mahwah, N.J.

10 No lo digo en un sentido despectivo. La suspensión del juicio en los diálogos interreligiosos prepara a la mente y al corazón para la posibilidad de un entendimiento con no-cristianos. 
patía no es una preferencia adelantada, una predilección garantizada, sino el fruto de ese amplio amor que hace del interés del vecino nuestro propio interés. No hay simpatía sin humildad, así como no hay empatía sin el don del entendimiento.

En tercer lugar, un diálogo productivo debe encaminarse a un entendimiento global de la religión en cuestión. Pues si éste se detiene en detalles insignificantes puede ser peligroso y confuso. Cada parte de la configuración de creencias y prácticas que componen a una religión debe ser considerada sólo como parte y reinstalada en el contexto global del cual fue tomada. Esta regla es especialmente importante en el caso de relatos mitológicos y en la interpretación de símbolos. Luego de trabajos precursores como las Mythologiques de Lévi-Strauss y los estudios de Ricoeur sobre el símbolo y la metáfora, uno no puede aventurarse justificadamente en la maleza del simbolismo religioso con la ingenua esperanza de recuperar ahí el significado de expresiones simbólicas en un nivel de significación inmediato. ${ }^{11}$ De igual manera, la determinación de géneros literarios de los tipos de discurso utilizado (el recurso lingüístico favorito del budismo, por ejemplo, es la vía negativa, mientras que en el cristianismo esto está generalmente reservado para la literatura mística). Y el enredo cultural de las referencias originales son todas de una importancia hermenéutica crucial en el intento por comprender global y contextualmente una religión que no es la propia.

Finalmente, en diálogos con religiones no-cristianas los puntos de convergencia han de ser rescatados y apreciados primero, dejando que las diferencias hablen por sí mismas. Es una experiencia interesante en encuentros correctamente conducidos, ecuménicos, ver que muy a menudo, aun bajo posiciones superficiales claramente contradictorias, aparece una corriente interna compartida por las partes opositoras. El diálogo, entonces, debe desarrollarse sobre las líneas de esta profunda posición, y es desde esta postura de complementariedad que debe ser construida una plataforma para una discusión posterior (referente a los contrarios o a las contradicciones según el ca-

"Ver, especialmente, P. Ricoeur, Interpretation. Theory (Fort Worth: Texas Christian (Iniversity, 1976) pp. 45-69. 
so). Para ilustrar este punto veamos el problema de la naturaleza del mal y algunos de los medios de liberación en el cristianismo y en las grandes religiones orientales.

La conciencia religiosa judeo-cristiana parte de la realización del estado pecaminoso del hombre. Las primeras páginas de la Sagradas Escrituras describen la desobediencia rebelde del hombre contra Dios. Para recuperarse del pecado se requiere que uno siga un camino de purificación que lleva de regreso a Dios, que es un padre misericordioso. Los medios del regreso son los sacramentos - canales de la gracia de Dios y portadores de la vida divina del alma.

El hinduismo y el budismo ven la raíz de todo mal en los deseos egoístas de un yo ignorante. Intentan liberar al hombre de las cadenas de pasiones y deseos excesivos, y reintegrarlo a (l) a realidad (ser) misma (o). La espiritualidad, aquí, es concebida principalmente dentro del contexto del monismo estricto, pero también, aquí y allá, especialmente en la literatura vedanta del hunduismo, se deja entrever una noción trascendente de Brahaman. De la misma manera la eficacia de la oración y alguna noción de gracia también aparece (especialmente en el budismo de Tierra Pura) en escena, pero obligatoriamente el Ser debe encontrar todos los recursos de liberación en sí mismo. De aquí el enorme esfuerzo que requiere de sus devotos.

En el taoísmo, confucianismo y en el sintoísmo japonés el mal toma la forma de una alienación de la naturaleza. Su meta es el establecimiento del hombre en armonía original con la naturaleza (Tao, Sinto) o en una vida humana, estructuralmente simple, dentro de la naturaleza (Confucio). Los medios para obtener esta meta son también, como en el budismo, esfuerzos personales, aunque las creencias místicas complementan a estas tres religiones para darles un grado superior de eficacia.

Desde esta lista parece que la naturaleza del mal y nuestra liberación de él se conciben de manera muy diferente en las religiones citadas. Mas las posiciones se juntan en la convicción compartida de que la existencia terrenal no es todo lo que hay para la vida humana y que, a través de un proceso de purificación, se alcanzará una perfección superior. El cristiano se sabe poseedor de estas verdades a través de la revelación divina. No 
necesita buscar en otro lado para discernir el misterio del mal, la verdadera naturaleza de purificación y la meta última de la vida humana. Las respuestas que tiene a estos misterios - pecado original, la gracia que Dios nos comunica a través de la muerte en la redención y resurrección de Cristo, el hijo de Dios, y la visión beatífica- rebasan por mucho a la más elevada introspección que las religiones no-cristianas hayan obtenido en sus respuestas de estas mismas preguntas. ${ }^{12}$ Sin embargo, así como los puntos de convergencia naturalmente refuerzan la doctrina cristiana, las diferencias también deben iluminarla al enfocar mejor su carácter sobrenatural. También debe reconocerse que muchas religiones no-cristianas - precisamente porque sus límites de eficacia no pueden rebasar los límites de sus propios recursos humanos- se han impulsado, con un esfuerzo más consistente, a un nivel más elevado e imaginativo de expresión ritual y verbal, que el que ha alcanzado el cristianismo como un todo. ${ }^{13}$ Desde esta perspectiva, el presente resurgimiento del interés por religiones orientales puede ser visto también como la expresión de una sed de formas religiosas que son más auténticas, exigentes y existencialmente penetrantes.

El cristiano, entonces, puede enriquecerse a través de por lo menos algunos aspectos de todas las otras religiones. Es su sagrada obligación escudriñar las formas en que el Espíritu mueve al alma humana a una verdadera metanoia, ya sea dentro o fuera de la Iglesia. Algunas de estas formas pueden ser confusas, molestas o desafiantes; otras pueden resultar más vigo-. rosas para la vida de los cristianos actuales que las toneladas de panfletos piadosos que aventamos diariamente sobre nuestra cansada generación precaria de lecturas. ¿Qué no la advertencia del Apóstol, "Intenta todo y conserva lo bueno", nos invita a hacer precisamente esto?

Aquí se ha argumentado que todas las religiones contie-

12 Desde luego el cristianismo es aquí el complemento del judaísmo. El islam, por otro lado, ha tomado mucho de la tradición judeo-cristiana.

is Estoy pensando en ritos paganos tales como las expiaciones de los muertos, las purificaciones, los sacriticios - no incluyo los humanos-o las danzas sagradas. El ritualismo (laborado de servicios budistas o el dinamismo de un matsuri sinto, sorprenden al observador cristiano, aún si conoce la belleza y la riqueza de, digamos, las liturgias ortodoxas (cristianas). 
nen alguna verdad sobre el hombre y su relación con Dios y que, consecuentemente, pueden incluso ayudar, directa o indirectamente, al creyente cristiano a tener una mejor comprensión de la palabra de Dios y a una apreciación más profunda de los recursos espirituales del cristianismo. Esta posición será ahora puesta a prueba al abordar un tema de gran importancia, tanto por su inmediata aplicación a la vida espiritual como por su gran popularidad en nuestros tiempos: la práctica de la oración y la meditación en las religiones orientales. La pregunta es la siguiente: ¿ cuede el cristiano unirse a esta práctica sin causarle daño a su propia fe y, si así lo fuera, puede beneficiarse con esto? Por razones prácticas, aquí voy a estar primordialmente interesado en el budismo zen, rama del mahayan al cual yo mismo he tenido un gran acceso. Pero confío que mis observaciones se aplicarán de igual manera, mutatis mutandis, al hinduismo y el hinayana o budismo tibetano. Luego de delimitar el espíritu de la oración en el budismo zen, lo confrontaré con el de la Iglesia -el ecclesia orans- y veré si el primero puede tener algún efecto positivo, o si transforma o enriquece al último.

\section{El espiritu de oración zen budista:} ¿puede ser integrado a la espiritualidad cristiana?

Si por oración queremos decir algún tipo de comunicación verbal con el Ser supremo, entonces la posición del budismo es ambigua con respecto a la oración. ${ }^{14}$ Incluso un encuentro superficial con doctrinas y prácticas budistas debe ser suficiente para convencer a cualquiera de la profunda desconfianza que los budistas sienten por las palabras. $\mathrm{O}$, al menos, eso parece. La razón de su desconfianza es el hecho de que las palabras crean una distancia, por decirlo así, entre el locutor y el objeto del cual se habla, y esto es una discriminación y alienación -esto es lo que más aborrecen los budistas.

De hecho, desde un punto de vista budista ¿ por qué debe uno rezar? La fuente de todo mal está en el Ser, pero en él tam-

14 Ciertamente que la oración es mucho más que una "comunicación verbal", pero alguna forma de verbalización es parte de cada oración. Las palabras son el vehículo del alma en la oración. 
bién, la fuente de liberación del mal. Para descubrir esta fuente uno necesita, primordialmente, observar profundamente el propio Ser. Además, la sabiduría (el dharma) se transmite de mente a mente en un destello de iluminación, no por comunicación verbal. Aunque si algo prepara para esto, es la práctica. El Camino, como tienden a decir los budistas zen, es "caminar sobre la brecha de los budas y patriarcas"; hacer las cosas que hacían ellos. Si se sigue fielmente este camino, la iluminación invadirá como relámpago algún día al practicante, y cuando esto suceda las palabras se volverán inútiles y toda la sabiduría adquirida se derrumbará en pedazos. ${ }^{15}$ Por esta razón los grandes maestros zen, especialmente en la tradición soto zen, acostumbraban exhortar a sus alumnos a no querer aprender o, incluso, estudiar los sutras, sino concentrarse en la forma más auténtica de autopenetración, la meditación. Este es el significado de la regla dorada del zen: "sólo sentado" (shikan taza).

Mas en otro sentido las palabras sí expresan lo inexpresable y pueden ser verdaderamente útiles para alcanzar el alumbramiento. Esto se pone especialmente de manifiesto en la importancia que el zen rinzai da a los koanes. Los koanes son acertijos verbales, aparentes sin sentidos, que, sin embargo, propiamente estudiados y dominados, abren la mente a la luz de la sabiduría budista. Por ejemplo, un conocido koan pregunta ¿ cuál es el sonido de una sola mano que aplaude? ${ }^{16} \mathrm{He}-$ cha así la preguntá no tiene sentido. Pero el aprendiz que lucha por entenderla eventualmente se dará cuenta que (para hablar en un estilo budista), el sonido está en todas partes y que una vez que uno es (se identifica con) el sonido mismo, el sonido de una o de dos manos no es diferente. Así, el verdadero significado de las palabras y textos debe ser encontrado en un nivel más elevado de significación. En este nivel el significado es más profundo y rico, y va más allá de los estrechos límites de una mera vocalización. Para el maestro Sung Yuan, "hablar no es cuestión de mover la lengua". ${ }^{17}$ discursivo.

15 En otras palabras, la introspección, aquí, toma el papel del razonamiento

${ }^{16}$ A diferencia de la mayoría de los koanes, éste no es de origen chino. Fue ideado por el maestró zen japonés, Hakuin, en el siglo dieciocho.

17 Toshihiko Izutsu, Toward a Philosophy of Sen Buddhism (Tehran, 1977), p. 99. 
Ir más allá del primer significado de las palabras es un ejercicio dialéctico, que invita tanto al locutor como al oyente a sobrepasar las limitaciones inherentes al lenguaje. Este es un esfuerzo constante en el budismo y la parte esencial de todo entrenamiento religioso. Es expresado enfáticamente por el maestro Wu-Men:

La escuela zen hace del espíritu de las palabras de Bukkna la base y de la no-puerta, el acceso al Dharma. Pero si sólo existe la no-puerta, ¿ cómo puede uno pasar? ¿no conoces el dicho: "lo que pasa por la puerta no es el tesoro de la casa"? ¿Cómo puede uno comprender mientras permanece atado a las palabras? El uso de las palabras es como pegarle a la luna con una vara o rascarse èl zapato por sentir comezón en el pie. ${ }^{18}$

Recalquemos en esta afirmación la dialéctica de puerta y barrera. La palabra del Buda es "no-puerta" mientras uno permanece atado a ella. Esto es, sabiendo la palabra del Buda como palabra, uno no ha avanzado ni el mínimo trecho en el dharma. Pero en cuanto uno penetra en el significado esencial de la palabra del Buda, la palabra se vuelve "la puerta", la entrada a la sabiduría iluminada. Sin esta transformación de las palabras, éstas no sólo fracasarán transmitiendo el dharma, sino que incluso lo esconderán, cubriéndolo como los zapatos nos cubren los pies.

Este también es el sentido de la a menudo citada pero rara vez comprendida afirmación del gran maestro Mumon: "Cuando conoces al Buda, lo matas; cuando conoces a los patriarcas, los matas. Al filo de la vida y la muerte, impones la perfecta libertad." 19 De nuevo, el significado de esta enigmática afirmación es que a menos que uno haya alcanzado la perfecta libertad -una libertad que es desligarse tanto de las palabras del Buda como del Buda mismo- uno no puede ser su fiel seguidor.

La ambivalencia que caracteriza el uso de palabras en general, a fortiori caracteriza la actitud del budismo hacia la orap. 56 .

18 Karlfield Durchheim, ed. The Grace of Zen (New York: Seabury Press, 1976),

19 Mumonkan, caso 1. 
ción. En ocasiones la oración es necesaria, pero en otras ocasiones necesita ser descartada, ya que la oración es sólo un paso intermedio entre la perfección y la imperfección, entre la iluminación y la ignorancia. Posiblemente una retrospectiva de la vida religiosa hindú, en la que radican las raíces del budismo, nos ayude a entender mejor esto.

En el hinduismo el camino a la perfección es el yoga, que significa literalmente "amarrarse a"o "estar unido a"con el Absoluto. Pero el hinduismo distinguió eventualmente tres formas de yoga, cada una conduce a la unión con el absoluto, y sin embargo sigue un camino diferente. El karma-yoga enfatiza la aceptación total de nuestra vida, y requiere una humilde sumisión a ella; bhakti-yoga es, esencialmente una forma de prácticas devotas; dhajana-yoga es el camino de la sabiduría, la meditación y la introspección, el cual conduce a la más elevada perfección y a la perfecta unión con la Realidad absoluta. La oración está esencialmente -aunque no exclusivamente- ligada con el bhakti-yoga, que también significa que no es un medio indispensable para la iluminación. Esta idea de oración es fundamental para la noción zen de perfección y explica su posición subordinada con respecto a la práctica de la meditación.

Por lo que a esto se refiere, es típico el silencio acerca de la oración en la obra clásica budista del siglov. El despertar de la $f e$. En la parte cuarta, "Sobre la fe y la práctica", la obra da una lista de cinco maneras que permiten al hombre perfeccionar su fe: caridad, observancia de los preceptos, paciencia, celo y observación clara ${ }^{20} \mathrm{Ni}$ una palabra sobre la oración. La "observación clara" encabeza la lista. Esto puede ser discutido ya que se refiere a un entendimiento luminoso de la realidad. Pero de cualquier manera es una perfección intelectual que sigue la línea de zazen, que significa "sentado en meditación". No es de extrañar, entonces, que los monasterios zen enfatizen la meditación más que la oración, lo cual culmina con los sesshins, periodos de meditación intensa y prolongada, que practican día y noche, sólo con interrupciones muy necesarias, por espacio de unos días o, incluso, durante todo un mes. Mas esto no quiere

20 The Awakening of Faith, trad, con comentario, Yoshito S. Hakeda (New York: Columbia University Press, 1967), p. 93. 
decir que la oración (en el sentido antes definido) esté ausente de los requerimientos de las prácticas espirituales del budismo. De hecho, la recitación de los sutras y los mantras (una forma de oración como el rosario) y el canto de himnos, son una práctica diaria en los monasterios y juegan un papel importante en la vida de cualquier devoto.

Aún hay más. El budismo mahayana se desarrolló bajo la noción de los bodhisattvas, que son, y fueron, intermediarios entre el hombre y los budas. Se puede recurrir a ellos para favores especiales e incluso el patriarca Dogen exhorta a sus monjes a rezarle a los "ángeles guardianes", quienquiera que sean éstos. ${ }^{21}$ Posiblemente veamos en todo esto una contradicción dentro de la espiritualidad budista, y a partir de esto hay, de hecho, una contradicción entre esta doctrina y su práctica. Pero es mejor ver esta tensión como una sola tensión entre "palabras" y "no-palabras", "puerta" y "no-puerta"-como otro ejemplo de la radicalmente dialéctica naturaleza de la espiritualidad budista. En efecto, en aras de llegar más allá de toda apariencia fenoménica el budismo debe negar toda afirmación, pero entonces, igualmente debe negar a la negación misma.

$\dot{c}$ Tiene todo esto alguna importancia para la espiritualidad cristiana? ¿ Puede ejercer la comprensión zen de la oración una influencia positiva sobre las maneras en que los cristianos rezan y sobre las formas en que intentan encontrar un nuevo sentido en la práctica de la oración? En pocas palabras, ¿ pueden las oraciones y prácticas budistas integrarse igualmente al cristianismo?

$\mathrm{Al}$ abordar un tema tan amplio uno necesita distinguir cuidadosamente entre las dimensiones o perspectivas de la pregunta, dado que la oración puede ser comparada con un poderoso árbol que tiende sus ramas y hojas hacia el cielo, repartiendo sus raíces a lo largo y hondo de la tierra, y sosteniéndose en un poderoso tronco que, a su vez, sirve de intermediario entre la copa y las raíces. Si esta imagen es paradigmática, también en la oración podemos distinguir por lo menos tres nive-

\footnotetext{
" 21 Esto aparece repetidamente en Regulations For Monasteries, Shobogenzo y Shobogenzo Zuimonki de Dogen.
} 
les: el psicológico, el filosófico y los estratos teológicos que tienen que ver en el encuentro del hombre con Dios.

No dudaré en afirmar que las teorías psicológicas que subyacen en la práctica de la oración en el budismo y las técnicas desarrolladas a partir de ahí son muy superiores a las que se conocen y se practican en el cristianismo "contemporáneo"; porque nosotros también hemos tenido, especialmente en los primeros siglos de la Iglesia, un acercamiento a la oración más desarrollado, más integrado y puramente sagrado. Los grandes capadocios y los Padres del desierto en el Oriente, los institutos de Casian e incluso la Regla Benedictina en Occidente, son algunos de los muchos testigos que indican que en el cuerpo y alma de la temprana vida de la Iglesia, los sentimientos, y las emociones formaban una unidad más dinámica e intensa, dirigida ésta a una elevatio mentis ad Deum, que lo que Occidente ha conocido por mucho tiempo ya bajo el concepto demasiado vago y particularizado de oración. Si bajo la influencia del hinduismo y el budismo empezamos a recobrar el sabor de lo que San Benito llama (siguiendo una larga tradición que le había sido transmitida) pura oratio - oración pura- no podemos menos que sentir agradecimiento hacia la influencia oriental por desempolvar las superficies de nuestras devociones de oración instantánea. Esto lo digo por algunos encuentros de primera mano con la meditación zen en los escenarios cristiano y budista. La profundización y apertura a dimensiones más amplias de mi vida de oración en el despertar (o inicio) de mi encuentro con el zen japonés, fue más grande de lo que yo esperaba. Esto lo atribuyo a una mayor apreciación del escenario de la conducta, la relación equilibrada de cuerpo y mente, y el espíritu del silencio y la sencillez en la oración. Para mayores detalles sobre la experiencia zen cristiana uno debe leer las destacadas obras de autores tales como los sacerdotes Enomiya-Lassalle, Demoulin o Kadowaki. ${ }^{22}$

La apreciación de los ingredientes filosóficos que componen la elaboración sistemática de una teoría de la oración en el

${ }^{22}$ Particularmente ilustrativas son el "Zen Way to Enlightenment" de Enomiya-Lasalle (London: Sheed and Ward, 1966); William Johnston, Cristian Zen (New York: Harper and Row, 1971); Heinrich Dumoulin, Zen Enlightenment (New York: Weatherhill, 1979). 
budismo es una tarea mucho más difícil y compleja de lo que fue la evaluación de los aspectos psicológicos. De entrada, toda la filosofía oriental -hinduismo, budismo, las filosofías de China y Japón- es básicamente filosofía religiosa. Ciertamente uno puede extraer de ellas una psicología, una cosmología, lógica o metafísica, pero la interpretación de estas ramas de la filosofía, consideradas aisladamente del contexto total de su empuje religioso, inevitablemente estrecharían, o incluso distorsionarían, su verdadero significado. Incluso la metafísica huayen u obras clásicas del budismo chino tales como El despertar de la fe o el Ensayo sobre el león de oro ${ }^{23}$ que supuestamente tratan de cuestiones metafísico-epistemológicas, están tan entretejidas con temas morales y religiosos que deberíamos considerarlas obras religiosas y evaluarlas como tales.

Pero incluso a la luz de esta filosofia religiosa debe agregarse una característica. La variedad de sistemas en el budismo es mucho mayor que lo que el incauto occidental imagina normalmente. Las diferencias abordan temas vitales tales como la naturaleza del Ser y la identidad personal, la naturaleza de la realidad cósmica, el nirvana, la iluminación, y otros. Por esta razón mantendré mis comentarios dentro de los confines del espíritu de la oración en el budismo zen, como se señaló anteriormente, y preguntaré si la práctica de la oración zen transformada en meditación pudiera ser, desde un punto de vista religioso-teológico, sabrosa o tal vez beneficiosa para el creyente cristiano. Voy a señalar, en primer lugar, los obstáculos que el cristiano practicante debe encontrar, juntándolos en tres observaciones de gran importancia.

Primero, la oración cristiana está dirigida a un Dios trascendental, señor del cielo y la tierra. Dios y hombre no están sobre la misma plataforma en el cristianismo; en medio de ellos permanece abierto el insondable vacío que se yergue entre el infinito y lo finito. El piadoso judío en el Antiguo Testamento exaltaba a Dios "sobre las alturas" (Sal. 57:5-11) y le reconocía una grandeza que pertenece sólo a Dios (Sal. 86:10). El

${ }^{23}$ Este clásico ensayo de Fa-tsang (649-712) da buena cuenta del idealismo epistemológico budista, al analizar las apariencias contra la realidad de un león de oro. 
Nuevo Convenio (Nuevo Testamento) sólo refuerza lo mismo cuando ordena, por ejemplo, que nadie debe jurar, "ya sea por el cielo, pues es el trono de Dios; o por la tierra, que es su pedestal"' (Mateo 5:34-35). La perspectiva cristiana es pues un universo en dos niveles, radicalmente diferente del monismo estricto del contexto religioso budista.

Segundo, el Dios de la fe cristiana es eminentemente personal: Ėl es tres personas en una sola naturaleza divina. La oración en el cristianismo es un diálogo y un verdadero encuentro, un asunto de corazón a corazón. "Debes orar", dijo Jesús, "así: Padre nuestro que está en el cielo..." (Mateo 5:9). Rezarle al Padre ("Padre nuestro") es reconocer que somos hijos e hijas, niños de Dios (Gal. 4:6; Lucas 11:11-13), y por esta razón el cristiano recurre a Él en todas sus necesidades y "en cada ocasión posible" (Ef. 6:18). En el budismo, por otro lado, la oración no puede más que permanecer como un mero ejercicio mental, una introspección hacia un ser más profundo con la esperanza de encontrar ahí la posibilidad de una reintegración esencial con la realidad misma. No es que la oración budista no pueda ser profunda -lo es, sólo que carece de ese aspecto yo-tú que le da un carácter personal único al balbuceo de los niños con sus padres, a las palabras que los amigos o los amantes intercambian entre sí. La oración cristiana, en todas sus formas, es interpersonal: una palabra viviente enviada a un Dios viviente.

Y por último, la oración del cristiano tiene una dimensión temporal, ya sea como acto de súplica, adoración o agradecimiento. Se murmura aquí y ahora, y su eficacia se sustenta en el acto histórico del sacrificio redentor de Jesucristo. Es por esto que para el cristiano no puede haber otro nombre por el cual uno se pueda salvar más que por el de Jesús, el Señor ( $\mathrm{He}$ chos 4:12). De nuevo, la diferencia con el budismo es sustantiva: no hay lugar para tal intersección de lo temporal con lo eterno y de lo humano con lo divino en el idealismo pancósmico de la Weltanschauung espiritual budista.

Estas (y seguramente más puntos afines podrían ser mencionados) son restricciones muy serias a la aplicación de la práctica budista zen de oración a la oración cristiana. Pero el reverso de la moneda también debe ser visto y apreciado. No- 
sotros, cristianos, podemos también contar fácilmente con la eficacia de la gracia de Dios (ex opere operato) y pasar por alto las consecuencias prácticas de la profunda introspección teológica que la gracia antecede a la naturaleza. Lo que esto significa va más allá de cuestiones de técnicas en la oración; señala la necesidad de orar con todo lo que tenemos y todo lo que somos. La muy lamentada ruptura entre la espiritualidad dominical y la que se dirige al resto de la semana es sintomática del profundo abismo que hay dentro del hombre occidental.

La englobadora y consistente búsqueda de la unidad en el budismo puede ejercer un muy necesitado efecto de sobriedad sobre nuestras a menudo dualistas ( $y$, de hecho, farisaicas) aproximaciones a la perfección, y pueden ayudarnos a redirigir nuestra atención a la importancia de un integracionismo vital en la vida espiritual. La desenfatización de "hablar" con el énfasis agregado de la meditación puede también actuar como un saludable incentivo hacia un tipo de espiritualidad más contemplativa, la cual estará más cerca de acuerdo con la comunidad de Jerusalén que se había reunido en torno a María, la madre del redentor, en la esperanza del Espíritu Santo.

Recientemente, en un periódico del Vaticano se publicó un interesante testimonio del obispo Bamruhtrakul de Tailandia, en el que describe las formas en que su encuentro con el budismo y su participación en lo que él ha denominado "Meditación cristiana asiática", ha profundizado en su propia comprensión de la "liberación del pecado" del hombre en contraposición a la doctrina de "liberación de la autocentralización" en el budismo. ${ }^{24} \mathrm{Y}$ el obispo agregó este bien pensado comentario: "Si la liberación de la autocentralización es sólo el aspecto negativo de la vida concentrada en Dios, en el Espíritu Santo, sería muy interesante estudiar si Buda recibió, usando la terminología cristiana, "la gracia" de la redención, expresada de acuerdo a la cultura religiosa de su tiempo. ${ }^{25}$

Subrayemos de esta cita el término "aspecto negativo". El budismo se expresa, como ya se señaló, a través de la vía nega-

24 En el Boletín de los Secretariatus pro nom-Christianis 17, no. 2 (citta del Vaticano, 1982): 239-247.

${ }^{25}$ En el Boletin de los Secretariatus pro non-Christianis, p. 246. 
tiva, sacando así la inefabilidad de la búsqueda religiosa. En nuestra cultura positivista inflada por un espíritu de autoconfianza, esto también puede ser un muy necesitado empuje para reactivar nuestro interés en la tradición mística cristiana, en donde encontramos una preocupación similar con expresiones a menudo muy similares a aquéllas de los grandes líderes espirituales de religiones orientales. Meister Eckhart, Tauler, Gertrudis de Hefta, el autor de la Nube del desconocido y San Juan de la Cruz son sólo unos cuantos ejemplos dé la gran y muy olvidada tradición mística occidental.

Para estar seguros, así como también Balthasar lo ha señalado, el ideal cristiano de perfección no es la espiritualidad de los místicos sino la de los santos. ${ }^{26}$ Es a aquéllos que buscan a Dios a través del sencillo pero heroico acto de amor, sean místicos o no, que Dios, se revela como un Padre amoroso. Ellos son los santos, los brillantes ejemplos de fe y vida cristianos. Mas, podemos preguntar, ¿qué no nosotros, en nuestro tiempo de autoconfianza y ciencias computarizadas, necesitamos hoy desesperadamente el reconocimiento de que el Dios del amor es un Dios de amor infinito, un misterio inefable y la fuente insondable del Ser? Los místicos (los carismáticos parece ser que han entendido esto bien) pueden devolvernos el extraviado don del asombro, de la sorpresa y la introspección. Esto es posiblemente lo que siempre sugirió Przywara cuando hablaba de Dios como semper maior, el cual siempre está trascendiendo nuestras limitadas posibilidades conceptuales. La apreciación de la vía negativa, que es también la vía mística, tan poderosamente sugerida por todas las religiones orientales, puede ser un saludable incentivo en esa dirección.

Pero, ¿ podemos ir más allá de meramente reconocer los efectos de la espiritualidad oriental sobre la espiritualidad cristiana como saludables incentivos o útiles consejos? ¿ podemos decir, o desear, que el cristiano también puede encontrar su Dios dentro y a través de la iluminada experiencia de las religiones no-cristianas, orientales? ¿ Puede el sénoor de Abraham, Isaac y Jacob, puede el Padre de nuestro señor Jesucristo reve-

26 "Christian and non-Christian Meditation" Word and Spirit Z (1980):147. En realidad, Balthasar se refiere aquí a los estudios de Jacques Albert Cuttat. 
larse al cristiano que participa en, digamos, una sesión intensiva sesshin del budismo zen?27

Me parece que aún no estamos preparados para responder apodícticamente a esta pregunta. Necesitamos más tiempo, más experimentación y posiblemente más humildad de cada lado para obtener más luz sobre la aparentemente impenetrable pregunta de "el sentido de Dios en el budismo". Acepto la prudente y honesta afirmación del padre jesuita William Johnston sobre este tema:

El trabajo precursor no es algo que deba ser tomado a la ligera o en forma caballeresca. Puede ser el llamado de algunos que han experimentado profundamente a Cristo en su propia cultura y están dispuestos a aceptar el cruce cultural, la angustia y el conflicto que necesariamente acompañan cualquier intento de reconciliar aparentes contrarios. ${ }^{28}$

Lo que necesitamos, entonces, es un diálogo continuo e intenso, abertura al Espíritu y obediencià en la fe. Este también fue el tema de los repetidos discursos del Papa Juan Pablo II en ocasión de su visita al lejano Oriente en 1981. Sólo haciendo esto podemos esperar, no con la ingenua esperanza de los eternos optimistas, sino con la esperanza de aquellos que depositan su confianza en Dios, que el diálogo religioso OrienteOccidente agrade tanto a Oriente como a Occidente. Pues como dijo Qoheleth hace mucho:

Así como no conoces el camino del viento o los misterios de una mujer embarazada, no podrás conocer el trabajo de Dios que está atrás de todo (Ecles. 11:5).

27 Ver John Bauker, The Religious Imagination and the Sense of God (Oxford: Clarendon Press, 1978), pp. 244-307.

${ }_{28}$ William Johnston, The Inner Eye of Love: Mysticism and Religion (San Francisco: Harper and Row, 1978), p. 86. 